\section{Genomic and Functional Characterization of a Novel Burkholderia sp. Strain AU4i from Pea Rhizosphere Conferring Plant Growth Promoting Activities}

\author{
Usha Devi ${ }^{1}$, Indu Khatri ${ }^{2}$, Reena V. Saini ${ }^{1}$, Lalit Kumar ${ }^{1}$, Devender Singh ${ }^{1}$, Aditi Gupta ${ }^{1}$, \\ Navinder Kumar ${ }^{2}$, Andrés Gárriz ${ }^{3}$, Srikrishna Subramanian ${ }^{2 *}$, Deepak Sharma ${ }^{2^{*}}$ and Adesh K. Saini ${ }^{1^{*}}$ \\ ${ }^{1}$ Department of Applied Sciences and Biotechnology, Shoolini University of Biotechnology and Management Sciences, Bajhol, Solan, HP, India \\ ${ }^{2}$ CSIR-Institute of Microbial Technology, Sector 39A, Chandigarh, India \\ ${ }^{3}$ UB3, Instituto de Investigaciones Biotecnológicas-Instituto Tecnológico de Chascomús/Universidad Nacional de General San Martín-Consejo Nacional de \\ Investigaciones Cientificas y Técnicas (IIB-INTECh/UNSAM-CONICET), Chascomús, Argentina
}

"Corresponding author: Adesh K Saini, Department of Applied Sciences and Biotechnology, Shoolini University of Biotechnology and Management Sciences, Bajhol, Solan, HP, India, Phone: +91-89882035238; Fax: 01792-308000; E-mail: sainiade@gmail.com

Deepak Sharma, CSIR-Institute of Microbial Technology, Sector 39A, Chandigarh, India, Phone: +91-1722695215; Fax: 0172-6665478; E-mail: deepaks@imtech.res.in

Srikrishna Subramanian, CSIR-Institute of Microbial Technology, Sector 39A, Chandigarh, India, Phone: +91-01726665483; Fax: 0172-6665478; E-mail: krishna@imtech.res.in

Rec date: Jul 25, 2015; Acc date: Sep 11, 2015; Pub date: Sep 15, 2015

Copyright: @ 2015 Devi U, et al. This is an open-access article distributed under the terms of the Creative Commons Attribution License, which permits unrestricted use, distribution, and reproduction in any medium, provided the original author and source are credited.

\begin{abstract}
Members of Burkholderia genus are gaining importance for their application in crop improvement by acting as plant growth-promoting rhizobacteria (PGPR), however, our knowledge about mechanisms of their plant growth promotion is limited. Herein, we aimed to isolate Burkholderia $s p$. from pea rhizosphere that confers plant growth promoting traits both in vitro and in vivo using pea seedlings as model. We have isolated a novel Burkholderia strain AU4i (B-AU4i) from pea rhizosphere that strongly promotes root and shoot growth in plantae. B-AU4i confers phosphate solubilization, indole-3-acetic acid production, N2 fixation, ammonia production, siderophore production, $\mathrm{HCN}$ production, and inhibits growth of pathogenic fungi both in vitro and in vivo experiments where we employed pea-seedlings as model system. Sequencing of B-AU4i genome using the Illumina-HiSeq 1000 technology reveals that it contains genes for the above-mentioned biofertilizer and biocontrol activities. The findings demonstrate the potential use of B-AU4i as plant growth promoter, which could be due to the presence of relevant genes in its genome. The current study improves our knowledge regarding the genes present in Burkholderia spp. that are involved in its plant growth promotion activities. B-AU4i strain can be used for improving agriculture productivity owing to its strong biofertilizer and biocontrol activity.
\end{abstract}

Keywords: Rhizosphere; Genomics; Plant pathology; Biocontrol

\section{Abbreviations}

PGPR: Plant Growth-Promoting Rhizobacteria; IAA: Indol-3-Acetic Acid; ifoR: Indolepyruvate Ferredoxin Oxidoreductase; igpS: Indole-3Glycerol Phosphate Synthase; GDH: Glucose Dehydrogenase; PQQ: Pyrroloquinoline Quinone

\section{Introduction}

Rhizosphere, the layer of soil influenced by the plant root, harbor microbes, known as plant growth-promoting rhizobacteria (PGPR), that confer a positive influence on the growth of plants [1]. The beneficial effects of PGPR are primarily due to their biofertilizer activities that include phosphate solubilization, production, phytase production, and nitrogen fixation; phyto hormone production like indol-3-acetic acid (IAA); biocontrol activities involving production of antifungal compounds, HCN, chitinase and siderophores [2-4]. Several PGPR strains have been tested in field trials and were proven to increase the productivity of economically important crops $[5,6]$. Genomes of PGPR strains including Serratia fonticola strain AU-P3 (3), Pseudomonas fluorescens Pf-5 and Bacillus sp. strain JS have been sequenced, which is helping to understand the correlation between genes and PGPR activities [7-10].

The genus Burkholderia includes at least 43 gram-negative bacilli species with exceptional metabolic versatility [11]. Beneficial members of Burkholderia genus can be free-living in the rhizosphere as well as epiphytic and endophytic, including obligate endosymbionts [11,12]. Two factors that can be attributed to the ecological versatility of members of this genus includes: huge coding capacity of their large multi-replicon genomes ranging from 6-9 Mb that allows them to be metabolically robust, and an array of insertion sequences in their genomes which promote genomic plasticity and general adaptability [13]. Similar to other PGPR strains, B. vietnamiensis, B. ubonensis, $B$. kururiensis and $B$. pyrrocinia show important biofertilizer and biocontrol activities [14-16]. B. phytofirmans PsJN exerts phenotypic effects throughout the whole life cycle of plants by modulating their transcriptional profiles [17]. However, the bacterial genes responsible for these activities remain still unidentified.

Herein, we have isolated a novel endophytic Burkholderia sp. strain (B-AU4i) from pea rhizosphere, which presents biofertilizer and biocontrol activities. Our in planta experiments strongly demonstrated the biological significance of B-AU4i in improving overall health of 
plants. Genome sequencing of B-AU4i revealed the presence of several genes that account for the mentioned biocontrol and biofertilizer activities, further strengthening its biotechnological application.

\section{Materials and Methods}

Pea roots were collected from crop fields in Himachal Pradesh, India. Loosely attached soil was removed, the root was shaken gently and the adhering rhizospheric soil was rinsed in $10 \mathrm{mM} \mathrm{MgSO} 4.7 \mathrm{H} 2 \mathrm{O}$ (Mgsol) $(1 \mathrm{mg} / \mathrm{ml})$, as described earlier [15] and then it was serially diluted and plated on Luria-Bertani (LB) agar plates. Colony morphology was analyzed and bacteria tested by gram staining. Genomic DNA from Gram-negative strains forming yellow colored colonies was isolated using DNA purification kit (Zymo Research). To identify bacterial species, 16S rRNA gene was amplified using primers FP (5'AGAGTTTGATCCTGGCTCAG) and RP (5'GGTTACCTTGTTACGACTT). The amplified DNA product was sequenced and the $16 \mathrm{~S}$ rRNA gene sequence analyzed using the BLAST program.

\section{Seed Experiments}

Pea seeds were surface sterilized with $70 \%$ ethanol and $1 \%$ sodium hypochlorite as described earlier [18], placed in petri-dishes containing muslin cloth moistened with distilled water and allowed to grow in the dark for six $\mathrm{d}$ at $25^{\circ} \mathrm{C}$. After six days (d), germinated seeds were dampened in a suspension of the bacterial strain $\left(7 \log \mathrm{CFU} \mathrm{ml} \mathrm{m}^{-1}\right)$ [19] and incubated at $25^{\circ} \mathrm{C}$. After $12 \mathrm{~d}$ seedlings were analyzed for their root length, shoot length, number of lateral roots, root hairs $\mathrm{mm}^{-1}$ of root length, fresh weight and dry weight [20]. In turn, seedlings were also used to check the endophytic nature of B-AU4i. With this purpose, root and shoot portions were cut at different time points and surface sterilized. After weighing, the samples were minced in $1 \mathrm{ml} \mathrm{Mgsol} \mathrm{buffer} \mathrm{and} \mathrm{serial} \mathrm{dilutions} \mathrm{were} \mathrm{plated} \mathrm{on} \mathrm{LB} \mathrm{agar} \mathrm{plates}$ to count CFU. Obtained colonies were matched with the original strain both biochemically and by $16 \mathrm{~S}$ rRNA gene sequencing.

\section{Genome Assembly and Annotation}

The genome of an isolated PGPR strain was sequenced using the Illumina-HiSeq 1000 technology. The assembly was performed by CLCbio wb6 (www.clcbio.com). The functional annotation was carried out as described earlier [7]. For the taxonomic characterization of bacterial species the 16S rRNA analysis was followed by creating Maximum Likelihood (ML) trees using recA gene by MEGA v6.0 [21]. Also, Multiple Locus Sequence Analysis (MLSA) was performed using seven housekeeping genes (atpD, gltB, gyrB, recA, lepA, phaC, and $\operatorname{trpB}$ ) [22]. As there were more than 60 Burkholderia genomes available at NCBI, whole genome information was further used to characterize the species using DNA-DNA hybridization (DDH) values from GGDC server $[23,24]$. The PGPR genes as mentioned in this study were retrieved from the Burkholderia genomes.

\section{Assays for Biofertilizer Activities}

Phosphate solubilization was analyzed on Pikovskaya's agar as described earlier [25]. Halo size was determined by subtracting the colony diameter from the total diameter. Ability of the cells to produce phytase enzyme was analyzed by spotting the cells on media containing sodium phytate as described earlier [26]. N2 fixation ability was analyzed as described earlier [27] by analyzing bacterial growth in nitrogen-free semisolid $\mathrm{BAz}$ medium containing (in gl-1): azelaic acid, 2.0; $\mathrm{K}_{2} \mathrm{HPO}_{4}, 0.4 ; \mathrm{KH}_{2} \mathrm{PO}_{4}, 0.4 ; \mathrm{MgSO}_{4} .7 \mathrm{H} 2 \mathrm{O}, 0.2 ; \mathrm{CaCl}_{2}, 0.02$; $\mathrm{Na}_{2} \mathrm{MoO}_{4} \cdot \mathrm{H}_{2} \mathrm{O}, 0.002 ; \mathrm{FeCl}_{3}, 0.01$; bromothymol blue, 0.075; agar, 2.3, and adjusting $\mathrm{pH} 5.7$ with $\mathrm{KOH}$. Formation of yellow pellicle was observed at a depth of one to four $\mathrm{mm}$ below the surface [15]. Quantification of IAA was carried out using the Salkowski assay [28]. Concentration of IAA was estimated using standard curves for authentic IAA. Ammonia production was analyzed by using Nessler's reagent $(0.5 \mathrm{ml})$ as described earlier [29].

\section{Biocontrol Activities}

Siderophore production was analyzed by spotting cells on Chrome azurol S agar plates as described earlier [30]. HCN production by bacteria was analyzed as described by Lorck (1948) [31]. Furthermore, in vitro antagonism of plant pathogenic fungi (Fusarium sp., Rhizoctonia sp., Rosellinia sp., and Alternaria $s p$.) by bacteria was tested by dual culture assay and zone of inhibition was measured [32]. To assess the antifungal effects of the bacterial strain in planta, surface sterilized pea-seeds were grown for six $d$ as described above, then infected with fungal spores $\left(1 \times 108 \mathrm{ml}^{-1}\right)$ and then dampened in a suspension of the bacterial strain $\left(7 \log \mathrm{CFU} \mathrm{ml}{ }^{-1}\right)$. The seeds were further incubated at $25^{\circ} \mathrm{C}$ for $10 \mathrm{~d}$ and compared with uninfected seeds. Similarly, the effects on gram (Cicer arietinum) and wheat seeds were also analyzed following the same protocol.

\section{Statistical Analysis}

Each experimental treatment was replicated four times. Column ttest was performed to compare means using the GraphPad Prism Version 5.02 for Windows (GraphPad Software; La Jolla, CA, USA) with a completely randomized analysis of variances $(p<0.0001)$. The $p$ values (two-tailed) were determined by One-sample $t$ test assuming $\alpha=0.05$ [33].

\section{Results}

\section{Isolation of growth-promoting Burkholderia sp. from pea rhizosphere}

Screening of randomly chosen 100 colonies isolated from pearhizosphere yielded 25 gram-negative strains showing yellowish and glossy colony morphology similar to Burkholderia sp. [16]. The strains were found to be non-spore forming, motile and strictly aerobic (data not shown). All the strains were analyzed for their ability to solubilize phosphate using Pikovskaya's agar and we found the best phosphate solubilization activity in one of the strain AU4i (described below). The $16 \mathrm{~S}$ rRNA gene of AU4i was sequenced and was found to be a continuous stretch of 1521 bp (released at NCBI, accession number: KF114029) that has $100 \%$ similarity with $B$. vietnamiensis strain SYe-6586 (accession number: FJ436055) and, 99\% identity with sequenced Burkholderia strain G4.

The B-AU4i strain was explored for its ability to promote seedling growth. Surface sterilized pea seeds were treated with B-AU4i as described in experimental procedures. Interestingly, after seven days (d) of treatment, B-AU4i stimulated root and shoot formation (Figure 1A). B-AU4i treatment stimulated the root length by $\sim$ four-fold and shoot length by two-fold (Table 1 , lane 1 vs. 2). Importantly, treated seedlings showed $\sim 50$ root hair $\mathrm{mm}^{-1}$ of root length while root hairs were absent in the untreated seeds even till $12 \mathrm{~d}$ (Table 1 , lane 1 vs. 2). 
Citation: Usha D, Indu K, Reena VS, Lalit K, Devender S, Aditi G, ,Navinder K, Andrés G,Srikrishna S, Deepak S, Adesh KS (2015) Genomic and Functional Characterization of a Novel Burkholderia sp. Strain AU4i from Pea Rhizosphere Conferring Plant Growth Promoting Activities. Adv Genet Eng 4: 129. doi:10.4/2169-0111.1000129

Page 3 of 8

To the best of our knowledge, this is the first report showing the role of Burkholderia sp. in stimulating root hair formation. Additionally, we found that there is a $\sim 1.5$-fold increase in total fresh weight and $\sim$ three- fold increase in dry weight of seedlings treated with B-AU4i compared to untreated ones (Table 1, lane 1 vs. 2). Similar experiments were performed with gram seeds and wheat grains, and we found that $\mathrm{B}-\mathrm{AU} 4 \mathrm{i}$ treatment also stimulated root and shoot formation in these species (Table S1A and S1B, respectively). We further went on to evaluate the endophytic nature of B-AU4i by extracting endophytes from seeds treated with B-AU4i as described above. Interestingly, we found the presence of B-AU4i since the second $\mathrm{d}$ of treatment in root samples and since the eighth $d$ in shoot samples (Figure 1B). Morphology of all the colonies obtained after plating the extracted endophytic samples was found to be similar to that of B-AU4i. Moreover, the identity of B-AU4i was confirmed by sequencing $16 \mathrm{~S}$ rRNA gene amplified from genomic DNA isolated from 10 colonies that were randomly picked. Therefore, we concluded that B-AU4i strain isolated from pea rhizosphere behave as an endophyte.

\begin{tabular}{|l|l|l|l|l|l|l|l|l|}
\hline Lane & Treatment given & $\begin{array}{l}\text { Root } \\
\text { length } \mathbf{( c m})\end{array}$ & Shoot length $\mathbf{( c m})$ & $\begin{array}{l}\text { Total no. of } \\
\text { roots }\end{array}$ & $\begin{array}{l}\text { Total no of Root } \\
\text { hairs }\end{array}$ & $\begin{array}{l}\text { Fresh } \\
\text { seedlings } \mathbf{( g )}\end{array}$ & $\begin{array}{l}\text { of } \\
\text { Dry wt. of seedlings } \\
\mathbf{( g )}\end{array}$ \\
\hline 1. & Control & 2.36410 .56 & 2.8110 .3 & 1513. & 9.40012 .503 & 1.38010 .27 & 0.410 .021 \\
\hline 2. & B-AU4i & 5.7210 .388 & 11.2211 .258 & 3812. & 39.5011 .434 & 3.50210 .475 & 0.65810 .126 \\
\hline 3. & F & 1.46010 .48 & 3.0910 .191 & 811.160 & 2.40011 .075 & 0.98710 .175 & 0.24410 .074 \\
\hline 4. & F+B-AU4i & 4.26010 .44 & 8.510 .657 & 2512. & 23.4012 .914 & 3.81910 .537 & 0.84810 .056 \\
\hline 5. & A & 2.8410 .334 & 3.33510 .309 & 611.370 & 8.20011 .687 & 1.04110 .052 & 0.34410 .049 \\
\hline 6. & A+B-AU4i & 4.6210 .336 & 9.2110 .281 & 3113. & 23.3012 .452 & 3.52110 .504 & 0.72210 .048 \\
\hline 7. & R & 2.7510 .48 & 3.7110 .328 & 1811. & 10.6012 .119 & 0.97410 .087 & 0.3610 .027 \\
\hline S. & R+B-AU4i & 3.0110 .179 & 8.52910 .533 & 3412. & 35.3012 .946 & 3.75710 .201 & 0.69610 .043 \\
\hline 9. & R & 2.64510 .22 & 3.13510 .287 & 1612. & 7.10011 .101 & 1.21710 .06 & 0.413710 .05 \\
\hline 10. & R+B-AU4i & 4.12010 .65 & 8.2310 .298 & 2312. & 21.0012 .625 & 4.63710 .447 & 0.7610 .056 \\
\hline
\end{tabular}

Table 1: Effects of B-AU4i treatment on the pea seedlings.

\section{Characterization and Analysis of the B-AU4i Genome}

Genome sequencing of Bv strains that promote seedling growth has not been performed yet. In order to get insight of the underlying basis that explain the beneficial effects of PGPR strains, we sequenced and analyze the genome of B-AU4i to look for the presence of genes that could promote seedling growth. The genome sequencing analysis of BAU4i resulted in more than 28 million paired-end reads (insert size of $350 \mathrm{bp}$ ) of length $101 \mathrm{bp}$. A total of 27,940,032 high-quality reads with approximately $300 x$ coverage were assembled with CLCbio wb6 (word size 23 and bubble size 50) to obtain 506 contigs (N50, 51,025 bp) of $9,267,974 \mathrm{bp}(9.2 \mathrm{Mb})$ and average $\mathrm{G}+\mathrm{C}$ content of $66 \%$. The genome sequence was submitted to Genbank under Accession number NZ_ASSI00000000.1. Functional annotation analysis revealed that the genome of B-AU4i contains 3 rRNA genes (5S-23S-16S) and 92 aminoacyl-tRNA synthetase genes. A total of 8649 coding regions (4477 genes transcribed from the positive strand and 4172 from the negative strand) were annotated by RAST server, of which 6161 (71\%) could be functionally annotated $[34,35]$.

The genome coding density of B-AU4i is $83 \%$ with an average gene length of $866 \mathrm{bp}$. The DNA sequence comparison of the genome sequences available on the RAST server revealed the closest neighbors of B-AU4i as Burkholderia cenocepacia J2315 (score 522) followed by Burkholderia cepacia R18194 (score 500), Burkholderia sp. 383 (score 486) and Burkholderia G4 (score 436). As most of the Burkholderia spp. live in close environment and have a complex evolutionary history
[36-39], we confirm the species of the isolated strain by fetching out recA, MLSA and whole genome information. The recA and MLSA tree revealed that the strain is closer to $B$. cenocepacia, even though the $\mathrm{DDH}$ value is below the minimum required to consider two species as the same $(>70 \%)$. In turn, the maximum DDH value was $50 \%$ with $\mathrm{B}$. sp. 383 and not a single available characterized genome had $>70 \%$ DDH value, suggesting that the strain belongs to a novel species. Furthermore, values below $90 \%$ were obtained by whole genome similarity matrix, generated for 64 Burkholderia genomes available at NCBI using Gegenees (Fragment size: 200 bp and sliding size: $100 \mathrm{bp}$ ). The similarity matrix was further subjected to splits tree and NJ tree was generated. The different species have clustered in separate clades and our strain was in proximity to B. sp. 383 (Figure 1C). Thus, the species was characterized as Burkholderia sp. AU4i (abbreviated as BAU4i).

Functional analysis of B-AU4i genes shows the presence of genes with a probable role in stimulating root formation. We found that BAU4i contains genes related to IAM pathway such as iaaH (coding indoleacetamide hydrolase) and iaaM (a trp transporter, encoding the trp monoxygenase that produces IAM) (Table S2). Additionally, we also found that B-AU4i contains genes encoding indolepyruvate ferredoxin oxidoreductase (abbreviated here as ifoR) and indole-3glycerol phosphate synthase (abbreviated here as igpS) that previously have been shown to be involved in IAA biosynthesis $[1,34]$.

Our analysis also demonstrated that B-AU4i contains genes involved in phosphate solubilization and N2 fixation. We identified an ORF sequence in B-AU4i showing a 95\% identity with the gene coding 
Citation: Usha D, Indu K, Reena VS, Lalit K, Devender S, Aditi G, ,Navinder K, Andrés G,Srikrishna S, Deepak S, Adesh KS (2015) Genomic and Functional Characterization of a Novel Burkholderia sp. Strain AU4i from Pea Rhizosphere Conferring Plant Growth Promoting Activities. Adv Genet Eng 4: 129. doi:10.4/2169-0111.1000129

Page 4 of 8

the acid phosphatase enzyme acpA in B. cenocepacia MC0-3 (accession no. YP-001779473) and 58\% identity with the acpA of Pseudomonas fluorescens SS101 (accession no. EIK59256) (Table S2). Furthermore, the production of organic acids by PGPR strains is related to their mineral phosphate-dissolving ability [35]. We found that B-AU4i contain genes encoding for glucose dehydrogenase (GDH) and the co-factor pyrroloquinoline quinone (PQQ) synthase complex that are involved in biosynthesis of gluconic acid which is involved in mineral phosphate solubilization [40]. Importantly, B-AU4i also contains genes coding for gabY/histidine permease membrane bound components shown to be involved in phosphate solubilization activity (98\% identical to polar amino acid ABC transporter inner membrane subunit of B. ambiferia, YP-001811506.1) [41]. We also found a protein tyrosine phosphatase-like phytase (PTPLP) encoding gene in B-AU4i that could release phosphorus from phytate [37]. PTPLP of B-AU4i strain has $40 \%$ identity with phytase gene of Selenomonas ruminantium subsp. Lactilytica [42]. Additionally, we also found the presence of nifQ gene (Table S2), implicated in the fixation of atmospheric nitrogen [43]. NifQ protein of B-AU4i is $80 \%$ identical to NifQ protein of $B$. cenocepacia (YP-002153405.1). Acetyl-CoA carboxylase subunit beta (accd) gene of B-AU4i is $99 \%$ identical to accd gene of Burkholderia sp. 383 (YP-372877.1). As a whole, the presence of the above-mentioned genes indicates that B-AU4i could confer phosphate solubilization and nitrogen fixation activities.

\begin{tabular}{|l|l|l|l|}
\hline \multicolumn{2}{|l|}{ Beneficial activities } & Genes & References \\
\hline \multirow{3}{*}{ Biofertilizer } & IAA production & Faced inaH. ifoR. igpS & {$[1-3]$} \\
\cline { 2 - 5 } & P-sol & $\begin{array}{l}\text { acp.4. genes coding for GDH. PQQ } \\
\text { synthase complex. GabY-Histidine } \\
\text { permease and phytase (PULP) }\end{array}$ & {$[4-6]$} \\
\cline { 2 - 5 } & N2 fixation & wig and aced & {$[7-8]$} \\
\hline \multirow{2}{*}{ Biocontrol } & Siderophore & pvdA. pvdF. pehDCB.4 operon. pchEFGN operon & {$[9-10]$} \\
\cline { 2 - 4 } & HCN & boa, hcnB and hcnC & {$[11]$} \\
\hline
\end{tabular}

Table S2: Genes of B-Ali4i involved in the biofertilizer and biocontrol activities.

Burkholderia spp. suppress many soil borne phytopathogens via secreting antifungal metabolites and siderophores $[12,44]$. We found that B-AU4i carries genes related to pyoverdine production ( $p v d A$ and $p v d F$ ), which is an iron (III) scavenger and an efficient iron (III) transporter [45], and pyochelin production (pyochelin biosynthetic operons pchDCBA and pchEFGHI) [46-48]. Moreover, we found genes related to $\mathrm{HCN}$ production ( $h c n A, h c n B$ and $h c n C$ ) (Table S2), which is implicated in biocontrol activity [49]. This suggests that B-AU4i could be able to confer biocontrol activity.

\begin{tabular}{|l|l|l|l|l|l|l|}
\hline \multicolumn{6}{|l|}{ Lane Treatment Root length Shoot length Total no. of Fresh weight Dry weight } \\
\hline no & given & $\mathbf{( c m )}$ & $\mathbf{( c m )}$ & roots & $\mathbf{( g )}$ & $\mathbf{( g )}$ \\
\hline 1. & Control & 7.800 .523 & 2.86010 .44 & 711. & $1.3800 \pm 0.27$ & 0.52110 .053 \\
\hline 2. & B-AU4i & 1612. & 5.4110 .364 & 1512. & $3.502 \_0.475$ & 1.1434 .128 \\
\hline 3. & F & 4.42910 .387 & 3.711 .051 & 412. & 0.98710 .175 & 0.49410 .054 \\
\hline 4. & F+B-AU41 & 18.5911 .409 & 6.1110 .185 & 1612. & 3.81910 .537 & 1.2820 .127 \\
\hline 5. & A & 4.72011 .629 & 4.710 .525 & $6-4.876$ & 1.0414 .052 & 0.52810 .034 \\
\hline 6. & A+B-AU4i & 18.31 .135 & 6.5910 .425 & 2112. & 3.5214 .504 & 1.23910 .065 \\
\hline 7. & R. & 6.7204 .732 & 3.9310 .427 & 511. & $0.974 \pm 0.086$ & 0.5564 .073 \\
\hline 8. & R+B-AU4i & 17.6311 .394 & 6.0910 .401 & 2012. & 3.75710 .201 & 1.3004 .043 \\
\hline 9. & R & 7.79011 .337 & 5.4710 .652 & 711. & 1.2174 .061 & 0.79684 .09 \\
\hline 10. & R+B-AU4i & 17.60 .9 & 7.3610 .299 & 1913. & $4.631+0.447$ & 1.5620 .112 \\
\hline
\end{tabular}

Table S1A: Effects of B-AU4i treatment on the gram seedlings. 
Citation: Usha D, Indu K, Reena VS, Lalit K, Devender S, Aditi G, ,Navinder K, Andrés G,Srikrishna S, Deepak S, Adesh KS (2015) Genomic and Functional Characterization of a Novel Burkholderia sp. Strain AU4i from Pea Rhizosphere Conferring Plant Growth Promoting Activities. Adv Genet Eng 4: 129. doi:10.4/2169-0111.1000129

Page 5 of 8

\begin{tabular}{|l|l|l|l|}
\hline \multicolumn{2}{|l|}{ Beneficial activities } & Genes & References \\
\hline \multirow{3}{*}{ Biofertilizer } & IAA production & Faced. inaH. ifoR. igpS & {$[1-3]$} \\
\cline { 2 - 4 } & P-sol & $\begin{array}{l}\text { Acp.4. genes coding for GDH. PQQ synthase complex. } \\
\text { GabY-Histidine permease and phytase (PULP) }\end{array}$ & {$[4-6]$} \\
\cline { 2 - 4 } & N2 fixation & wig and aced & {$[7-8]$} \\
\hline \multirow{2}{*}{ Biocontrol } & Siderophore & pvdA. pvdF. pehDCB.4 operon. pchEFGN operon & {$[9-10]$} \\
\cline { 2 - 4 } & HCN & boa, hcnB and hcnC & {$[11]$} \\
\hline
\end{tabular}

Table SIB: Effects of B-AU4i treatment on the wheat seedlings.

\section{Analysis of Biofertilizer Activities of B-AU4i}

Firstly, we checked phosphate solubilization activity of B-AU4i and found that it formed a halo-zone of $22 \mathrm{~mm}$ after $72 \mathrm{~h}$ due to the solubilization of tricalcium phosphate in Pikovskaya's media (Figure S1A). Our results were similar to those previously reporting phosphate solubilization activities in the Bv strain [16]. B-AU4i cells also formed a halo zone on phytase specific agar medium after $48 \mathrm{~h}$ (Figure S1B) due to the dephosphorylation of sodium phytate suggesting that BAU4i could play a role in liberating phosphorus from organic compounds such as phytates. Furthermore, we analyzed IAA production using Salkowski reagent [28] and found that cells of BAU4i (1 OD600) produced $16 \pm 1.5 \mu \mathrm{g} \mathrm{ml}^{-1}$ or $9 \pm 0.2 \mu \mathrm{g} \mathrm{ml}^{-1}$ of IAA with or without the amendment of tryptophan in the culture media, respectively. Thus, stimulation of root proliferation in the bacterized seedlings (Figure $1 \mathrm{~A}$ ) could be due to the secretion IAA by B-AU4i.

\section{Biocontrol Activity by B-AU4i}

The presence of genes for siderophore production in the B-AU4i strain suggests that it can be used as biocontrol agent [49]. In this trend, B-AU4i colonies gave orange colored halo-zones in the in vitro assays using CAS dye, indicating the release of siderophores that quench Fe from the medium (Figure 2A). Moreover, HCN production by PGPR is also correlated with their biocontrol ability [49]. Accordingly, we found that the B-AU4i strain was able to change the color of filter papers soaked in picric acid from yellow to orange, indicating its ability for $\mathrm{HCN}$ production (Figure $2 \mathrm{~B}$ ).

In order to confirm the antifungal activity of B-AU4i, we checked its ability to suppress the growth of phytopathogenic fungi in vitro by using dual culture method [27]. Our results demonstrate that B-AU4i efficiently suppressed the growth of Fusarium sp. (70\%), Rhizoctonia sp. (70\%), Alternaria sp. (60\%), and Rosellinia sp. (88\%), (1 vs. 2 in Figure $2 \mathrm{C}-2 \mathrm{~F})$. The above-mentioned in vitro experiments implicate that B-AU4i could be a strong biocontrol PGPR. To test if B-AU4i can be used for crop protection, we checked its capability to restrain the effects of Fusarium sp. and Rhizoctonia sp. on pea seedlings. Treatment of pea seeds with phytopathogenic fungi greatly reduced root formation (Figure 1A control vs Figure 3A F and 3B R). Interestingly, pretreatment of seeds with B-AU4i rescued this inhibitory effect (Figure $3 \mathrm{~A}$ F vs. F+B-AU4i, Figure 3B R vs R+B-AU4i, Figure 3C A vs $\mathrm{A}+\mathrm{B}-\mathrm{AU} 4 \mathrm{i}$ and Figure 3D R vs R+B-AU4i).
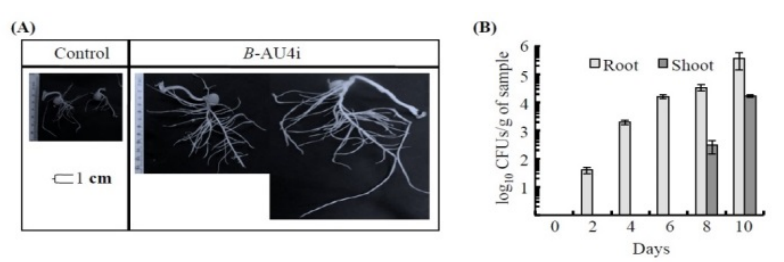

(C)

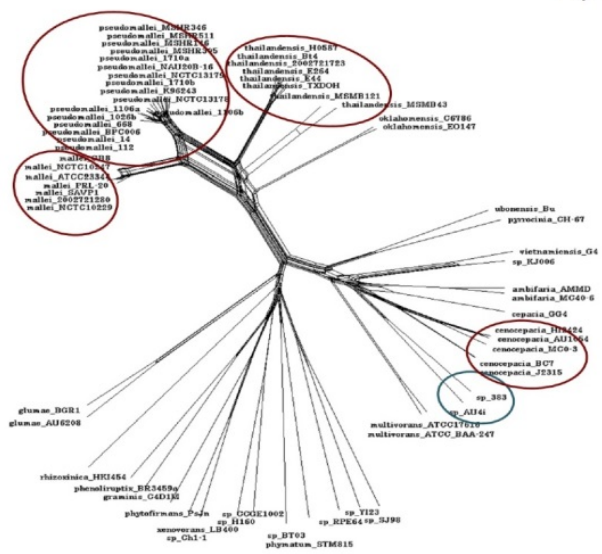

Figure 1: (A) B-AU4i stimulates root and shoot formation. After $6 \mathrm{~d}$ of growth in the dark, surface sterilized pea seeds in triplicate were treated with Mgsol (control panel) or with a B-AU4i suspension in Mgsol (107 cells ml-1) (B-AU4i panel) and the seeds were allowed to grow for $12 \mathrm{~d}$. Scale: $1 \mathrm{~cm}$. (B) B-AU4i is endophytic. Seeds were treated as described in (A) and root and shoot samples were excised at mentioned time points and surface sterilized. The samples were minced in Mgsol and CFUs were enumerated. (C) NJ tree of 64 Burkholderia spp. The similarity matrix generated by Gegenees was converted to newick format and NJ tree was generated using Splitstree. All the strains belonging to same species have clustered together in a clade as shown encircled (maroon color). Our strain has clustered with B. sp. 383 circled by blue color. 
Citation: Usha D, Indu K, Reena VS, Lalit K, Devender S, Aditi G, ,Navinder K, Andrés G,Srikrishna S, Deepak S, Adesh KS (2015) Genomic and Functional Characterization of a Novel Burkholderia sp. Strain AU4i from Pea Rhizosphere Conferring Plant Growth Promoting Activities. Adv Genet Eng 4: 129. doi:10.4/2169-0111.1000129

Page 6 of 8
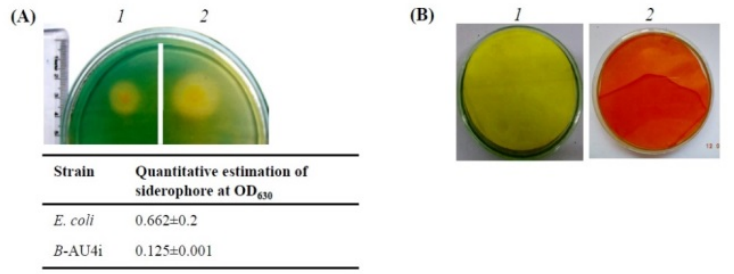

(C)
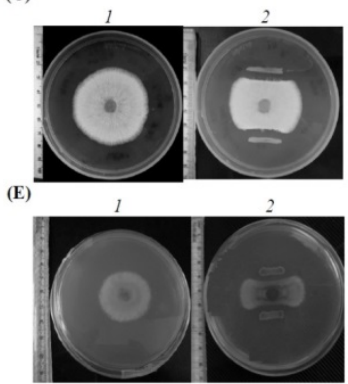

(D)

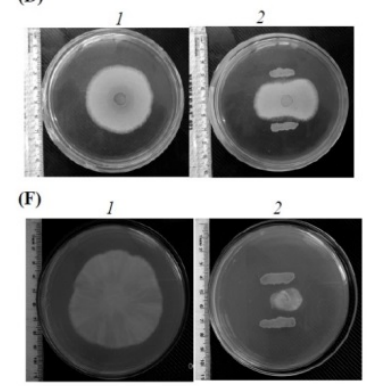

Figure 2: Biocontrol activities of B-AU4i strain. (A) Siderophore release. Cells were spotted on Chrome azurol $S$ agar plates and incubated for $72 \mathrm{~h}$ at $30^{\circ} \mathrm{C}$. (B) HCN production. Cells were streaked on agar plate having nutrient broth amended with glycine $(4.4 \mathrm{~g} / \mathrm{l})$. A Whatman filter paper one pre-soaked in $2 \%$ sodium carbonate in $0.5 \%$ picric acid solution was placed in the lid of glass plate. Formation of orange to red colour was observed after five $\mathrm{d}$ at $30^{\circ} \mathrm{C}$. (C-F) In vitro antifungal activity. Fungal disc of plant pathogenic fungi Fusarium sp. (C), Rhizoctonia sp. (D), Alternaria sp. (E) and Rosellinia sp. (F) was placed in the center of potato dextrose agar plate panel 1 and 2. B-AU4i was streaked at two $\mathrm{cm}$ away from the disc in panel 2.

\section{Discussion}

Burkholderiales play crucial ecological role pertaining to their biofertilizer, biocontrol and bioremediation activities and were found to be symbiotically associated with many crop plants as rhizobacteria or endophytes [38]. Owing to their biological versatility and wide host range they are now been considered as important PGPR. We isolated $\mathrm{B}-\mathrm{AU} 4 \mathrm{i}$ from the rhizosphere of pea plants and found that the strain promoted seedling growth of pea, wheat and gram. These results were found to be in agreement with previous reports showing that Burkholdaria spp. increased root and shoot formation in rice and sugarcane [27,37-39]. In addition, endophytic nature of B-AU4i in pea seedlings was confirmed using viability counts in root and stem tissues.

B-AU4i showed various biofertilizer attributes. For instance, we found that it conferred phosphate solubilization and phytase activity, which could be due to the production of GA as a result of GDH activity $[43,50]$ and the production of PTPLP phytase. In comparison to B-AU4i, Burkholderia sp. strain G4 contained a low molecular weight PTPLP that does not contain the consenus sequence motif HisCys-(X)5-Arg present in the PTPLP. The presence of PTPLP in B-AU4i implicates its role in solubilizing phytate, a form of organic phosphorous not readily available to plants, and thus contributes to plant growth promotion by increasing their assimilation of phosphorous [51]. Additionally, B-AU4i contained genes related to

IAA production. In this trend, we found that both IAM and IPyA pathways could be involved in IAA production. It is tempting to hypothesize that B-AU4i secretes IAA and thus boosts root proliferation, lateral root formation and root hair development. In turns, the presence of genes related to nitrogen fixation fits with the diazotrophic nature of B-AU4i. Besides biofertilizer activity, B-AU4i also conferred biocontrol activity and showed remarkable effects both in vitro and in planta experiments in controlling the deleterious effects of plant pathogenic fungi. Biocontrol attributes of B-AU4i could be related to the production of siderophores, which can be produced by genes related to pyoverdine or pyochelin biosynthesis, as well as HCN production via enzymes encoded by honABC genes.

(A)

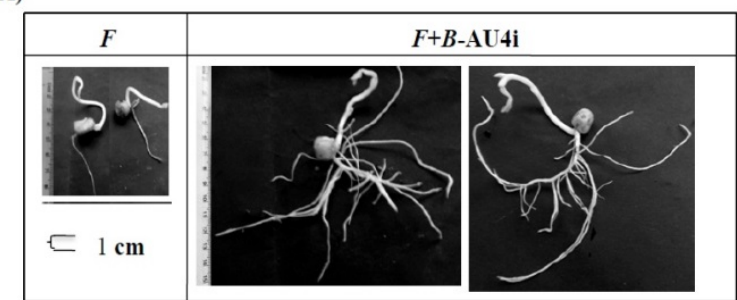

(B)

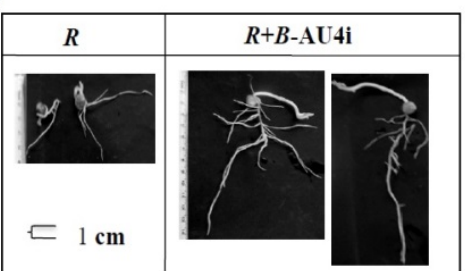

(C)

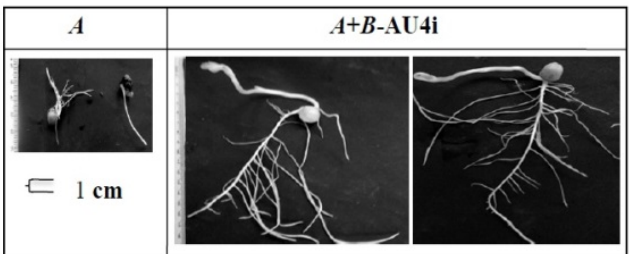

(D)

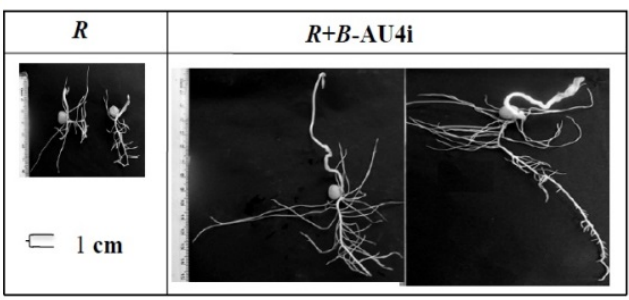

Figure 3: Antagonism of phytopathogenic fungi by B-AU4i in planta. (A-D) As described in Figure 1A, 100 germinated seeds taken and were treated either with fungal spores ( $(\mathrm{A})$ panel $\mathrm{F}$ is Fusarium sp.; (B) panel $\mathrm{R}$ is Rhizoctonia sp.; (C) panel $\mathrm{A}$ is Alternaria sp. and (D) panel $\mathrm{R}$ is Rosellinia sp.) or with fungi and $\mathrm{B}-$ AU4i together ((A) panel F+AU4i is Fusarium sp. and B-AU4i ; (B) panel R+AU4i is Rhizoctonia sp. and B-AU4i ; (C) panel A+B-AU4i is Alternaria sp. and B-AU4i and (D) panel $\mathrm{R}+\mathrm{B}-\mathrm{AU} 4 \mathrm{i}$ is Rosellinia sp. and B-AU4i). 
Citation: Usha D, Indu K, Reena VS, Lalit K, Devender S, Aditi G, ,Navinder K, Andrés G,Srikrishna S, Deepak S, Adesh KS (2015) Genomic and Functional Characterization of a Novel Burkholderia sp. Strain AU4i from Pea Rhizosphere Conferring Plant Growth Promoting Activities. Adv Genet Eng 4: 129. doi:10.4/2169-0111.1000129

Page 7 of 8

\section{Acknowledgment}

This work was supported by a FAST-track grant of the Department of Science and Technology (grant: SR/FT/LS-108/2012).

\section{References}

1. Loper JE, Henkels MD, Shaffer BT, Valeriote FA, Gross H (2008) Isolation and identification of rhizoxin analogs from Pseudomonas fluorescens Pf-5 by using a genomic mining strategy. Appl Environ Microbiol 74: 3085-3093.

2. Ahmad F, Ahmad I, Khan MS (2008) Screening of free-living rhizospheric bacteria for their multiple plant growth promoting activities. Microbiol Res 163: 173-181.

3. Zhang X, Huang Y, Harvey PR, Ren Y, Zhang G, et al. (2012) Enhancing plant disease suppression by Burkholderia vietnamiensis through chromosomal integration of Bacillus subtilis chitinase gene chil13. Biotechnol Lett 34: 287-293.

4. Singh RK, Kumar DP, Solanki MK, Singh P, Srivastva AK, et al. (2013) Optimization of media components for chitinase production by chickpea rhizosphere associated Lysinibacillus fusiformis B-CM18. J Basic Microbiol 53: 451-460.

5. van Rhijn P Vanderleyden J (1995) The Rhizobium-plant symbiosis. Microbiol Rev 59: 124-142.

6. Spaink HP, Kondorosi A, Hooykaas PJJ (1998) The Rhizobiaeceae: Molecular biology of model plant-associated bacteria. Dordrecht, The Netherlands: Kluwer Acad.

7. Devi U, Khatri I, Kumar N, Kumar L, Sharma D, et al. (2013) Draft genome sequence of a plant growth-promoting rhizobacterium, Serratia fonticola strain AU-P3(3). Genome Announc 1: 1-2.

8. Peñaloza-Vazquez A, Mena GL, Herrera-Estrella L, Bailey AM (1995) Cloning and sequencing of the genes involved in glyphosate utilization by Pseudomonas pseudomallei. Appl Environ Microbiol 61: 538-543.

9. Song JY Kim HA, Kim JS, Kim SY, Jeong H, et al. (2012) Genome sequence of the plant growth-promoting rhizobacterium Bacillus $\mathrm{sp}$ strain JS. J Bacteriol 194: 3760-3761.

10. Paulsen IT, Press CM, Ravel J, Kobayashi DY, Myers GS, et al. (2005) Complete genome sequence of the plant commensal Pseudomonas fluorescens Pf-5. Nat Biotechnol 23: 873-878.

11. Compant S Nowak J, Coenye T, Clément C, Ait Barka E (2008) Diversity and occurrence of Burkholderia spp. in the natural environment. FEMS Microbiol Rev 32: 607-626.

12. Partida-Martinez LP, de Looss CF, Ishida $K$, Ishida $M$, Roth $M$, et al (2007) Rhizonin, the first mycotoxin isolated from the zygomycota, is not a fungal metabolite but is produced by bacterial endosymbionts. Appl Environ Microbiol 73: 793-797.

13. Lessie TG Hendrickson W, Manning BD, Devereux R (1996) Genomic complexity and plasticity of Burkholderia cepacia. FEMS Microbiol Lett 144: 117-128.

14. Parke JL Gurian-Sherman D (2001) Diversity of the Burkholderia cepacia complex and implications for risk assessment of biological control strains. Annu Rev Phytopathol 39: 225-258.

15. Estrada-De Los Santos P, Bustillos-Cristales R, Caballero-Mellado J (2001) Burkholderia, a genus rich in plant-associated nitrogen fixers with wide environmental and geographic distribution. Appl Environ Microbiol 67: 2790-2798.

16. Madhaiyan M, Poonguzhali S, Kwon SW, Song MH, Sa T (2008) Molecular characterization of Burkholderia strains isolated from rice cultivars (Oryza sativa L.) for species identification and phylogenetic grouping. J Microbiol Biotechnol 18: 1005-1010.

17. Poupin MJ Timmermann T, Vega A, Zuñiga A, González B (2013) Effects of the plant growth-promoting bacterium Burkholderia phytofirmans PsJN throughout the life cycle of Arabidopsis thaliana. PLoS One 8: e69435.
18. Takehisa H Sato Y, Igarashi M, Abiko T, Antonio BA, et al. (2012) Genome-wide transcriptome dissection of the rice root system: Implications for developmental and physiological functions. Plant J 69: 126-140.

19. Onofre-Lemus J, Hernandez-Lucas I, Girard L, Caballero-Mellado J (2009) ACC (1-Aminocyclopropane-1-Carboxylate) Deaminase activity, a widespread trait in Burkholderia species, and its growth-promoting effect on tomato plants. Appl Environ Microbiol 75: 6581-6590.

20. Gahoonia TS, Nielsen NE (2004) Barley genotypes with long root hairs sustain high grain yields in low-P field. Plant Soil 262: 55-62.

21. Tamura K Stecher G, Peterson D, Filipski A, Kumar S (2013) MEGA6: Molecular Evolutionary Genetics Analysis version 6.0. Mol Biol Evol 30: 2725-2729.

22. Baldwin A, Mahenthiralingam E, Thickett KM, Honeybourne D, Maiden MC, et al. (2005) Multilocus sequence typing scheme that provides both species and strain differentiation for the Burkholderia cepacia complex. J Clin Microbiol 43: 4665-4673.

23. Auch AF, Klenk HP, Göker M (2010) Standard operating procedure for calculating genome-to-genome distances based on high-scoring segment pairs. Stand Genomic Sci 2: 142-148.

24. Agren J, Sundstrom A, Hafstrom T, Segerman B (2012) Gegenees: Fragmented alignment of multiple genomes for determining phylogenomic distances and genetic signatures unique for specified target groups. PLoS One 7: e39107.

25. Smyth EM, McCarty J, Navin R, Khan MR, Dow JM, et al. (2011) In vitro analyses are not reliable predictors of the plant growth promotion capability of bacteria; a Pseudomonas fluorescens strain that promotes the growth and yield of wheat. J Appl Microb 111: 683-692.

26. Quan C Zhang L, Wang Y, Ohta Y (2001) Production of phytase in a low phosphate medium by a novel yeast Candida krusei. J Biosci Bioeng 92 : 154-160.

27. Caballero-Mellado J, Onofre-Lemus J, Eatrada-de Los Santos P, MartInezAguilar L (2007) The tomato rhizosphere, an environment rich in nitrogen-fixing Burkholderia species with capabilities of interest for agriculture and bioremediation. Appl Environ Microbiol 73: 5308-5319.

28. Gutierrez CK, Matsui GY, Lincoln DE, Lovell CR (2009) Production of the phytohormone indole-3-acetic acid by estuarine species of the genus Vibrio. Appl Environ Microbiol 75: 2253-2258.

29. Cappuccino JC, Sherman N (1992) In: Microbiology: A Laboratory Manual Benjamin/cummings, New York.

30. Schwyn B, Neilands JB (1987) Universal chemical assay for the detection and determination of siderophores. Anal Biochem 160: 47-56.

31. Lorck H (1948) Production of hydrocyanic acid by bacteria. Plant Physiol 1: $142-146$.

32. Ross IL, Alami Y, Harvey PR, Achouak W, Ryder MH (2000) Genetic diversity and biological control activity of novel species of closely related pseudomonads isolated from wheat field soils in South Australia. Appl Environ Microb 66: 1609-1616.

33. Bazarian JJ, Zhu T, Zhong J, Janigro D, Rozen E, et al. (2014) Persistent, long-term cerebral white matter changes after sports-related repetitive head impacts. Plos One 16: 9e94734.

34. Ouyang J, Shao X, Li J (2000) Indole-3-glycerol phosphate, a branchpoint of indole-3-acetic acid biosynthesis from the tryptophan biosynthetic pathway in Arabidopsis thaliana. Plant J 24: 327-333.

35. Rodríguez H, Fraga R (1999) Phosphate solubilizing bacteria and their role in plant growth promotion. Biotechnol Adv 17: 319-339.

36. Vandamme P, Holmes B, Vancanneyt M, Coenye T, Hoste B, et al. (1997) Occurrence of multiple genomovars of Burkholderia cepacia in cystic fibrosis patients and proposal of Burkholderia multivorans sp. nov. Int J Syst Bacteriol 47: 1188-1200.

37. Caballero-Mellado J, Martínez-Aguilar L, Paredes-Valdez G, Santos PE (2004) Burkholderia unamae sp. nov., an N2-fixing rhizospheric and endophytic species. Int J Syst Evol Microbiol 54: 1165-1172.

38. Govindarajan M, Balandreau J, Muthukumarasamy R, Revathi G Lakshminarasimhan C (2006) Improved yield of micropropagated 
Citation: Usha D, Indu K, Reena VS, Lalit K, Devender S, Aditi G, ,Navinder K, Andrés G,Srikrishna S, Deepak S, Adesh KS (2015) Genomic and Functional Characterization of a Novel Burkholderia sp. Strain AU4i from Pea Rhizosphere Conferring Plant Growth Promoting Activities. Adv Genet Eng 4: 129. doi:10.4/2169-0111.1000129

Page 8 of 8

sugarcane following inoculation by endophytic Burkholderia vietnamiensis. Plant Soil 280: 239-252.

39. Perin L, Martínez-Aguilar L, Castro-González R, Estrada-de Los Santos P, Cabellos-Avelar T (2006) Diazotrophic Burkholderia species associated with field-grown maize and sugarcane. Appl Environ Microbiol 72: 3103-3110.

40. Babu-Khan S, Yeo TC, Martin WL, Duron MR, Rogers RD (1995) Cloning of a mineral phosphate-solubilizing gene from Pseudomonas cepacia. Appl Environ Microbiol 61: 972-978.

41. Nakashima BA, McAllister TA, Sharma R, Selinger LB (2007) Diversity of phytases in the rumen. Microb Ecol 53: 82-88.

42. Puhl AA, Greiner R, Selinger LB (2008) A protein tyrosine phosphataselike inositol polyphosphatase from Selenomonas ruminantium subsp. lactilytica has specificity for the 5-phosphate of myo-inositol hexakisphosphate. Int J Biochem Cell Biol 40: 2053-2064.

43. Siddavattam D, Singh M, Klingmüller W (1993) Structure of the nifQ gene from Enterobacter agglomerans 333 and its overexpression in Escherichia coli. Mol Gen Genet 239: 435-440.

44. Tenorio-Salgado S, Tinoco R, Vazquez-Duhalt R, Caballero-Mellado J, Perez-Rueda E (2013) Identification of volatile compounds produced by the bacterium Burkholderia tropica that inhibit the growth of fungal pathogens. Bioengineered 4: 236-243.

45. Meyer JM (2000) Pyoverdines: Pigments, siderophores and potential taxonomic markers of fluorescent Pseudomonas species. Arch Microbiol 174: $135-142$.
46. Heinrichs DE, Poole K (1993) Cloning and sequence analysis of a gene (pchR) encoding an AraC family activator of pyochelin and ferripyochelin receptor synthesis in Pseudomonas aeruginosa. J Bacteriol 175: 5882-5889.

47. Reimmann C, Serino L, Beyeler M, Haas D (1998) Dihydroaeruginoic acid synthetase and pyochelin synthetase, products of the pchEF genes, are induced by extracellular pyochelin in Pseudomonas aeruginosa. Microbiol 144: 3135-3148.

48. Reimmann C, Patel HM, Serino L, Barone M, Walsh CT (2001) Essential PchG-dependent reduction in pyochelin biosynthesis of Pseudomonas aeruginosa. J Bacteriol 183: 813-820.

49. Laville J, Blumer C, Von Schroetter C, Gaia V, Défago G, et al. (1998) Characterization of the honABC gene cluster encoding hydrogen cyanide synthase and anaerobic regulation by ANR in the strictly aerobic biocontrol agent Pseudomonas fluorescens CHA0. J Bacteriol 180: 3187-3196.

50. Unno Y, Okubo K, Wasaki J, Shinano T, Osaki M (2005) Plant growth promotion abilities and microscale bacterial dynamics in the rhizosphere of Lupin analysed by phytate utilization ability. Environ Microbiol 7: 396-404.

51. Singh B, Satyanarayana T (2011) Microbial phytases in phosphorus acquisition and plant growth promotion. Physiol Mol Biol Plants 17: 93-103. 